\title{
Wacana Identitas Disabilitas dalam Film What They Don't Talk When They Talk about Love (2013)
}

\author{
Izza Fidaul Jihad \\ Departemen Ilmu Komunikasi, Universitas Airlangga, Jalan Dharmawangsa Dalam No.4-6, \\ Surabaya 60286, Indonesia. Email: izza.fidaul.jihad-2016@fisip.unair.ac.id
}

\begin{abstract}
A B S S T R A C T
This study is a film text analysis study that aims to describe the disability discourse in the film What They Don't Talk When They Talk About Love (2013), which is represented and distributed to the audience regarding disability identity discourse in Indonesia today. This research is significant because of the representation of people with disabilities rarely shown as a figure and central issue. The film What They Don't Talk When They Talk About Love (2013) is a film directed by Mouly Surya that raises the big theme of the life of a person with a disability that is rarely shown primarily in presenting representations of people with disabilities that are humanist. This research method is a qualitative text-based analysis using film discourse interpretation by Jenna Wildfeuer to uncover the discourse of identity of disability in the film by doing two stages to understand and construct the meaning of the film namely the formal description of the inference process and functional analysis of the communicative purposes. The results of this study indicate that identity of disability in this film is through social interaction as something that is not bodily, but an environment that is not inclusive or discourse on the limited access of persons with hearing impairments communicating in society, through social relations persons with disabilities are shown as sexual beings and empowered over his body or discourse on sexuality and the exploration of the body of persons with disabilities, and through character representations that exist in the community or depictions of stories encountered in daily life.
\end{abstract}

Keywords: discourse; disability; identity; film discourse interpretation.

\begin{abstract}
A B S T R A C T
Penelitian ini adalah studi analisis teks film yang bertujuan untuk menguraikan wacana disabilitas dalam film What They Don't Talk When They Talk. About Love (2013) yang direpresentasikan dan didistribusikan kepada penonton terkait wacana identitas disabilitas di Indonesia saat ini. Penelitian ini menjadi penting diteliti karena representasi penyandang disabilitas jarang ditampilkan sebagai tokoh dan central issue. Film What They Don't Talk. When They Talk. About Love (2013) adalah film arahan Mouly Surya yang mengangkat tema besar kehidupan romansa penyandang disabilitas, sebuah tema yang jarang sekali ditampilkan utamanya dalam menghadirkan representasi penyandang disabilitas yang humanis. Metode penelitian ini adalah kualitatif text-based analysis dengan menggunakan film discourse interpretation milik Jenna Wildfeuer, untuk mengungkap wacana identitas disabilitas dalam film, dengan melakukan dua tahapan untuk memahami sekaligus mengonstruksi makna yang ada pada film yaitu formal description of the inference process dan functional analysis of the communicative purposes. Hasil penelitian ini menunjukkan identitas disabilitas dalam film tersebut ditunjukkan melalui interaksi sosial sebagai sesuatu yang tidak menubuh melainkan lingkungan yang tidak inklusif atau terbatasnya akses penyandang disabilitas rungu-wicara dalam berkomunikasi di masyarakat, melalui relasi sosial penyandang disabilitas diperlihatkan sebagai makhluk seksual dan berdaya atas tubuhnya atau wacana seksualitas dan eksplorasi tubuh penyandang disabilitas, dan melalui representasi karakter yang dapat ditemui di masyarakat atau penggambaran cerita yang dijumpai dalam keseharian.
\end{abstract}

Kata kunci : diskursus; disabilitas; identitas; film discourse interpretation.

\section{A. PENDAhuluan}

Berbicara mengenai media dan disabilitas tentu hal pertama yang menjadi soal adalah perihal penghadiran kembali penyandang disabilitas atau representasi di media. Dua masalah yang mengemuka ketika berbicara tentang representasi penyandang disabilitas di media adalah underrepresentation (kurang direpresentasikan) dan misrepresentation (kesalahan 
merepresentasikan). Representasi kehadiran penyandang disabilitas di media sangat sedikit (underrepresented) dan monolitik, sehingga menjauhkan masyarakat nondisabilitas dari realita kompleksitas kehidupan penyandang disabilitas yang beragam, representasi yang salah atau sering keliru (misrepresented) dalam hal ini penggambarannya tidak tepat atau bahkan tidak adil pada penyandang disabilitas ini kemudian berdampak pada posisi sosial mereka (Thaniago, 2018).

Representasi penyandang disabilitas dalam film-film layar lebar di Indonesia dengan mengambil tema besar disabilitas atau karakter utama sebagai penyandang disabilitas, minim secara jumlah. Hal ini kemudian meninggalkan tanda tanya atas alasan terjadinya fenomena ini. Menurut data dari World Health Organization (WHO) sebanyak 24 juta penduduk di Indonesia merupakan penyandang disabilitas (Thaniago, 2018), yang artinya sekitar 10 persen dari populasi Indonesia atau secara kasar 1 dari 4 penduduk di Indonesia adalah penyandang disabilitas. Namun dalam praktik-praktik keseharian, jarang sekali penyandang disabilitas dapat ditemui, apalagi representasi dari penyandang disabilitas di media pada layar kaca maupun layar lebar. Ketika representasi penyandang disabilitas di media ada, tidak jarang penggambarannya tidak utuh, seolah-olah penyandang disabilitas memiliki keanehan atau berbeda hidupnya dengan orangorang nondisabilitas (Wood, 2012).

Film What They Don't Talk When They Talk about Love (yang kemudian disebut Don't Talk Love) adalah film yang disutradarai dan ditulis oleh Mouly Surya pada tahun 2013. Dalam film ini, hampir semua karakter adalah penyandang disabilitas. Film ini mengungkapkan cerita-cerita cinta dan penggambaran kehidupan romansa penyandang disabilitas yang tidak jauh berbeda dengan kehidupan nondisabilitas. Film ini menceritakan kehidupan remaja di sebuah sekolah luar biasa (SLB) yang ditampilkan sebagaimana kehidupan remaja pada umumnya, termasuk bagaimana para tokoh ini membangun hubungan romantis. Film ini pernah diputar dalam festival film bergengsi yaitu Sundance Film Festival pada tahun 2013.

Penulis membedah dan mengurai wacana identitas disabilitas dalam film ini karena film ini memiliki cerita yang unik dan cukup menarik bagi peniliti, terutama dalam memberikan diskursus alternatif mengenai identitas disabilitas. Selain itu, film ini berlatar tempat di Indonesia sehingga melalui film ini pembahasan mengenai wacana identitas disabilitas di Indonesia menjadi relevan. Perhatian atau fokus penulis adalah pada wacana identitas disabilitas yang dihadirkan dalam film What They Don't Talk When They Talk About Love.

Identitas menurut Stuart Hall adalah sesuatu yang bersifat imajiner atau diimajinasikan keutuhannya. Identitas dimaknai sebagai sebuah produksi sehingga ia bukan merupakan esensi yang tetap melainkan selalu dalam proses dan bertransformasi (Hall, 1996). Identitas adalah sesuatu yang bersifat dinamis, dapat berubah sesuai dengan cara pandang masyarakat dan perubahan yang terjadi dalam sistem. Berbeda dengan Stuart Hall, De Fina menjelaskan bahwa identitas dipandang bukan sebagai produk tetapi sebuah proses yang terjadi dalam interaksi sosial yang terpatri pada praktik-praktik wacana keseharian (De Fina, 2006). Dengan kata lain identitas tidak lahir begitu saja, melainkan dibentuk oleh unsur-unsur masyarakat.

Konstruksi atas realitas yang diperkenalkan oleh Berger dan Luckman secara umum menjelaskan bahwa realitas dikonstruksi secara sosial ketika seseorang atau kelompok berinteraksi bersama dalam sebuah sistem sosial. Sehingga masyarakat dengan individu-individu yang saling berinteraksi pun saling memengaruhi perilaku satu sama lain.

Di dalam interaksi sosial individu-individu ini kemudian secara aktif dan subjektif menciptakan sebuah realitas yang kemudian dialami dan dimiliki individu-individu lainnya. Hal ini kemudian menjadi norma-norma sosial. Begitu pun dengan konstruksi identitas simbolik 
berpengaruh pada bagaimana suatu masyarakat mengetahui, mempersepsi, dan memahami terutama pada kelompok-kelompok marjinal, misalnya penyandang disabilitas.

Penting untuk dipahami bahwa ada beragam cara dimana representasi identitas berada pada tubuh, termasuk bagi penyandang disabilitas. Tubuh penyandang disabilitas dianggap berbeda dari tubuh "normal". Pengkategorian penyandang disabilitas sebagai sesuatu yang berbeda adalah ideologi yang sudah mendalam dan terus-menerus diperkuat oleh struktur sosial, kebijakan, dan sikap dari budaya yang ditentukan untuk melihat disabilitas atau kecacatan sebagai sesuatu yang tidak "normal." Ableisme (ableism) adalah istilah yang paling sering digunakan untuk menggambarkan sikap dan relasi kuasa yang mengkategorikan dan mendefinisikan kemampuan seseorang dengan batasan yang dirasakan tubuh dan pikirannya (Bernardi, 2009). Ableisme merupakan perwujudan atas sebuah konsep (mengenai disabilitas yang berdasar pada perbedaan bersifat fisik atau terletak pada tubuh) yang dilekatkan kepada individu yang dianggap lain dan tidak sesuai dengan standar yang dikonstruksi atau dianggap sebagai suatu norma. Disabilitas sebagai sebuah konsep (immaterial, tidak bersifat fisik) yang diciptakan oleh orang-orang ablebodied ini kemudian diberikan kepada orang-orang yang tidak sama dengannya, sehingga disebutlah orang-orang ini dengan penyandang disabilitas (disabled people atau people with disabilities) hanya karena perbedaan yang bersifat material (fisik, tampak) yang telah dikonstruksi. Hal ini kemudian menjadikan identitas penyandang disabilitas seolah-olah hanya bertumpu dan terpusat pada tubuhnya saja.

Dari paparan mengenai identitas khususnya identitas penyandang disabilitas yang telah dijabarkan maka identitas sebagai suatu konsep ini dilihat sebagai suatu konstruksi sosial dan merupakan hasil interaksi dengan lingkungannya. Sehingga dalam penelitian ini, identitas penyandang disabilitas sebagai suatu konsep yang luas dan abstrak, dilihat pada bagaimana interaksi sosial penyandang disabilitas dan relasi sosial penyandang disabilitas (baik dengan penyandang disabilitas maupun nondisabilitas).

Terdapat dua pendekatan besar yang mendasari pendefinisian dari disabilitas itu sendiri, pendekatan sosial atau social model dan pendekatan medis atau medical model. Dua pendekatan ini kemudian yang menjadi dasar yang penting dan krusial dalam memaknai disabilitas itu sendiri.

Pada pendekatan medis, penyandang disabilitas dilihat atau diidentifikasi pada hal-hal yang "kurang" dalam tubuhnya. Model ini berangkat dari hasil biomedis dan melihat bahwa disabilitas adalah hasil dari kondisi fisik yang intrinsik bagi individu (bagian dari tubuh individu itu sendiri), yang dapat mengurangi kualitas hidup individu dan menyebabkan kerugian yang jelas bagi individu tersebut.

Studi disabilitas dengan pendekatan kritis kemudian berupaya mengembangkan cara baru untuk memahami disabilitas. Studi ini dikembangkan dari konsep-konsep dasar yang sekarang dikenal tentang konstruksi sosial dari ekslusi (social construct of exlusion). Dengan cara yang hampir sama dengan kelompok-kelompok marjinal lainnya yang mengekspos cara-cara lingkungan yang diskriminatif dan mencegah inklusi penuh mereka, gerakan penyandang disabilitas menolak gagasan yang diterima secara umum bahwa disabilitas adalah masalah pribadi dalam tubuh individu yang rusak. Menurut Garland Thompson sama seperti bagaimana saat ini kita mengenali kompleksitas dalam memahami ras atau jenis kelamin yang tampak "alami" dan naluriah, demikian juga kita mulai menyelidiki lebih kritis perbedaan tubuh lainnya sebagai identitas (Ellis \& Kent, 2010).

Hal ini yang kemudian menyebabkan munculnya model sosial disabilitas yang mendefinisikan kembali disabilitas sebagai sesuatu yang terpisah dari tubuh. Menurut pandangan ini, disabilitas adalah sesuatu yang diciptakan atau dikonstruksi secara sosial dan berbeda dari "kecacatan" yang 
menggambarkan atribut fisik. Model sosial ini berpendapat bahwa batasan dalam fungsi fisik atau mental seseorang menjadi disable karena dampak dari struktur sosial yang ada (Ellis \& Kent, 2010).

Pembukaan Konvensi PBB menyatakan disabilitas adalah sebuah konsep yang terus berubah dan disabilitas adalah hasil interaksi antara orang yang penyandang disabilitas dengan hambatan perilaku dan lingkungan yang menghambat partisipasi penuh dan efektif di tengah masyarakat secara setara dengan orang lain. Dengan kata lain, disabilitas adalah hasil interaksi antara masyarakat yang sifatnya tidak inklusif. Menurut Konvensi Mengenai Hak-Hak Penyandang Disabilitas (Convention On The Right Of Person With Disabilities) yang telah diratifikasi dengan Undang Undang No. 19 tahun 2011 tentang Pengesahan Convention On The Right Of Person With Disabilities, penyandang disabilitas adalah mereka yang memiliki keterbatasan fisik, mental, intelektual, atau sensorik dalam jangka waktu lama dimana ketika berhadapan dengan berbagai hambatan, hal ini dapat menghalangi partisipasi penuh dan efektif mereka dalam masyarakat berdasarkan kesetaraan dengan yang lainnya.

Masih terbatasnya akses bagi penyandang disabilitas dalam membuat maupun mengkonsumsi seni, utamanya seni visual menjadikan penyandang disabilitas kurang dan asing dengan bentukbentuk seni visual yang cukup lazim dikonsumsi oleh penyandang disabilitas di luar negeri atau pada negara-negara maju. Tidak hanya akses penyandang disabilitas dalam seni, budaya, dan media itu sendiri, bahkan sedikit sekali studi atau penelitian di Indonesia yang memiliki ketertarikan pada studi disabilitas pada seni, budaya, dan media. Sehingga, pergerakan sosial (social movement) pada penyandang disabilitas di Indonesia baru memperjuangkan kesetaraan hak-hak dasar seperti ketersediaan akses pada ruang-ruang publik namun sangat kurang misalnya pada keterbukaan dalam memproduksi dan/atau mengonsumsi karya seni dalam berbagai bentuk.

Di Indonesia, sejak tahun 2015 muncul suatu gagasan dan gerakan bernama bioskop bisik. Bioskop bisik adalah kegiatan menonton film melalui bisikan. Setiap penyandang disabilitas tuna netra dibisikkan penjelasan atau deskripsi adegan tanpa dialog dan membantu membisikkan konteks adegan untuk dialog-dialog yang membutuhkan penjelasan oleh seorang relawan agar mendapatkan pengalaman menonton suatu film. Kegiatan ini berupaya untuk meningkatkan kepedulian dan inklusivitas dalam menikmati sinema, termasuk penyandang disabilitas (Movanita, 2017).

Tidak hanya bioskop bisik, di Indonesia kini mulai merebak kepedulian atas inklusivitas menonton bagi para penyandang disabilitas. Festival Film Dokumenter 2018 (FFD) di Yogyakarta misalnya, meluncurkan satu program khusus bertajuk "The Feelings of Reality". Bekerjasama dengan VOICE GLOBAL, program ini berniat memperluas pengaruh film-film yang menyuarakan isu disabilitas dengan cara menayangkan film dokumenter berbasis Virtual Reality (VR). Medium baru ini dipilih karena kemampuannya menampilkan realitas yang lebih dekat dengan audiens. Program "The Feelings of Reality" ini akan berlangsung selama tiga tahun, yakni 2018 sampai 2020. Di luar pemutaran, bentuk program yang akan dijalankan berupa workshop dan produksi film dokumenter berbasis VR. Selain itu, program ini juga akan mengadakan open call untuk para pembuat film di Indonesia, dengan empat daerah tujuan utama: DKI Jakarta, Jawa Barat, Jawa Tengah dan Nusa Tenggara Barat. Ditambah juga distribusi dan eksibisi delapan film dokumenter berbasis VR ke sekolah-sekolah dan komunitas-komunitas. Program ini diharapkan untuk meningkatan kesadaran mengenai isu-isu disabilitas melalui pengalaman menonton yang membawa realitas baru serta menimbulkan perubahan perspektif masyarakat dalam melihat isuisu disabiltas (FFD, 2018). Baik bioskop bisik maupun Program "The Feeling of Reality" ini 
merupakan itikad baik terciptanya ruang-ruang sinema yang lebih emansipatif dan menjangkau lebih banyak aspek.

Meski ada perkembangan dalam menciptakan pengalaman menonton dan menikmati sinema yang inklusif di Indonesia atau menciptakan ruang-ruang sinema yang lebih emansipatif, namun masih ada beberapa pekerjaan rumah bersama terkait disabilitas dan sinema di Indonesia. Hal terberat misalnya adalah dalam menghadirkan kembali penyandang disabilitas dalam medium audio-visual seperti dalam film yang humanis dan tidak menghakimi. Dalam medium seni film misalnya, film dengan tema besar atau membawa topik mengenai hubungan romansa penyandang disabilitas jumlahnya tidak banyak. Hal ini kemudian berimbas pada bagaimana masyarakat luas mempersepsi mengenai penyandang disabilitas berikut kemampuan mereka dalam mencintai maupun memiliki hubungan percintaan. Representasi yang sedikit ini juga mempengaruhi pengetahuan masyarakat luas terhadap bagaimana penyandang disabilitas mengisi kehidupan sehari-hari mereka sehingga menjauhkan masyarakat dalam memahami penyandang disabilitas secara utuh dan tidak menghakimi.

Menurut Stuart Hall film adalah sebuah sistem representasi dimana praktik-praktik pemaknaan dilakukan (Hall, 1997). Graeme Turner dalam bukunya mengungkapkan bahwa film merupakan suatu praktik penandaan sehingga film ialah suatu kumpulan tanda dan lambang yang dikonstruksi sedemikian rupa untuk menyampaikan suatu makna (Turner, 1999). Teks film dalam konteks ini bekerja seperti bahasa yang memuat kode-kode atau tanda-tanda yang berfungsi untuk memproduksi makna-makna. Sehingga film yang dilihat sebagai sistem representasi tidak dibuat dengan keadaaan vakum, melainkan film sebagai teks ideologi secara relasional dan kontekstual (Kellner, 1995). Namun dalam memahami film sebagai teks tentu akan berbeda dengan memahami teks biasa. Robert Kolker mengungkapkan bahwa film sebagai sebuah teks terdiri dari kumpulan gambar, kata-kata, dan bunyi-bunyian yang saling berhubung dalam sebuah konteks, yang dapat membentuk cerita atau narasi (Kolker, 1998). Namun, dalam memahami film sebagai teks bahasa film akan berbeda dengan teks lainnya. Perlu untuk mengetahui bahasa film dan tata bahasa (grammar) film. Menurut Villarejo melalui mise-en-scene kita dapat melihat manifestasi bahasa secara jelas dalam film. Villarejo kemudian menjabarkan ada enam komponen dalam miseen-scene, yaitu setting, lighting, kostum, rambut, make up, dan perilaku pemain (Villarejo, 2007).

Dalam memahami komponen-komponen pada mise-en-scene, tentu perlu juga memahami sinematografi. Sinematografi ini berkaitan dengan angle kamera, framing, dan pergerakan kamera. Selain itu dalam memahami pergerakan kamera, perlu untuk memahami macam-macam bentuk shot. Dalam bukunya Grammar of the Shot, Thompson dan Bowen menjelaskan bahwa jenis-jenis shot dan pemilihan angle tertentu akan memengaruhi pemunculan makna dalam pemikiran audiens (Thompson \& Bowen, 2009). Menurut Villarejo penyuntingan (editing) dan bunyi-bunyian (sound) juga menjadi penting dalam memahami film (Villarejo, 2007). Penyuntingan adalah teknik menggabungkan satu adegan dengan adegan yang lain hingga menjadi satu kesatuan yang utuh. Sound berupa elemen bunyi-bunyian terdiri atas speech, music, dan noise. Speech tidak hanya terbatas pada dialog meski dialog adalah unsur utama dalam narasi film. Noise adalah special effect yang ditambahkan dalam film.

\section{B. METODE}

Berbeda dari semiotik film yang mencari analogi-analogi antara film dan bahasa pada level sintaks serta komposisi semantik untuk mendeskripsikan mekanisme decoding sebuah film, Janina Wildfeuer dalam bukunya Film Discourse Interpretation menawarkan metode baru dalam menganalisis sebuah teks film (Wildfeuer, 2014). Wildfeuer mencoba merumuskan framework 
atau kerangka berpikir tentang film discourse interpretation sebagai cara untuk memahami film sekaligus mengonstruksi makna yang dimunculkan melalui keterkaitan antarelemen (multimodal) pada teks film secara komprehensif (Fitranisa, 2016).

Wildfeuer mengungkapkan bahwa pemaknaan (atas film) muncul karena interaksi antarelemen seperti gambar, bunyi, musik, gestur, dan efek kamera yang tergabung melalui proses penyuntingan dalam bentuk alur yang linear dan kronologis (Wildfeuer, 2014). Metode ini menjadikan interaksi antarelemen dalam film menjadi hal yang penting karena interaksi antarelemen menentukan keseluruhan struktur dan koherensi film serta menjelaskan makna dan interpretasi film sebagai sebuah teks. Interpretasi film sebagai proses relational meaning-making melibatkan penonton untuk aktif dalam membuat asumsi-asumsi berdasarkan tanda atau simbol yang muncul dalam teks film melalui interaksi anatarelemen dalam film.

Wildfeuer menjelaskan mengenai Logic of Film Discourse Interpretation yang kemudian dijabarkan oleh Intan Fitranisa dalam tesisnya mengenai aplikasi metode film discourse interpretation. Fitranisa menjelaskan bahwa dalam melakukan metode film discourse interpretation terdapat dua tahapan yang perlu dilakukan untuk memahami sekaligus mengonstruksi makna yang ada pada film yaitu formal description of the inference process dan functional analysis of the communicative purposes (Fitranisa, 2016).

Pada tahap formal description of the inference process, analisis dilakukan dengan menggunakan logic of film discourse interpretation untuk mengeksplorasi keterkaitan serta interpretasi koherensi elemen-elemen film. Logic of film discourse interpretation itu sendiri dapat dibedakan dalam dua proses. Proses pertama ialah The Logic of Information Content: berupa bahasa formal yang mendeskripsikan representasi semantik mengenai konten dari discourse. Sedangkan proses kedua adalah, The Logic of Constructing the Logical Form of Discourse: berupa aksioma-aksioma yang dibutuhkan untuk mendefinisikan discourse relations dalam discourse structure. Dalam proses ini terdapat dua bagian, yaitu glue logic atau glue language yang merupakan proses untuk membentuk pola-pola logika dari discourse segment, dan discourse update yang memperhitungkan proses terjalinnya sumber informasi yang berbeda dengan relasi retorika. Hasil dari interpretasi tahap pertama formal description kemudian diteruskan pada tahap yang kedua yaitu functional analysis of the communicative process (Wildfeuer, 2014).

\section{HASIL DAN PEMBAHASAN}

Menurut Stuart Hall, identitas merupakan produk sehingga selalu dalam proses dan bertransformasi. Sebagai sesuatu yang bersifat dinamis, ia dapat berubah sesuai dengan cara pandang masyarakat dan perubahan yang terjadi dalam sistem (Hall, 1996). Identitas sebagai suatu konsep yang kemudian dilekatkan pada penyandang disabilitas disebut sebagai identitas disabilitas. Media, termasuk film, kemudian memiliki peran dalam memproduksi, mewacanakan, dan mendistribusikan identitas disabilitas kepada masyarakat yang nantinya akan menjadi perbincangan dan dipersepsi oleh masyarakat. Dalam mengupas identitas disabilitas dalam film, penulis kemudian menelisik cara-cara film ini menunjukkan identitas disabilitas yang merujuk pada bagaimana interaksi, relasi, dan representasi mengenai penyandang disabilitas dalam film ini.

Melalui interaksi sosial penyandang disabilitas dalam film Don't Talk Love (2013), penyandang disabilitas ditunjukkan bahwa ada banyak cara dalam berkomunikasi atau menyampaikan pesan. Pada Edo dan Fitri misalnya, keduanya dapat berkomunikasi dengan surat braille. Hal ini dimungkinkan karena adanya keinginan dari Edo untuk belajar menulis surat dengan huruf braille dan adanya alat-alat yang dibutuhkan dalam menulis huruf braille seperti stylus dan reglet. 


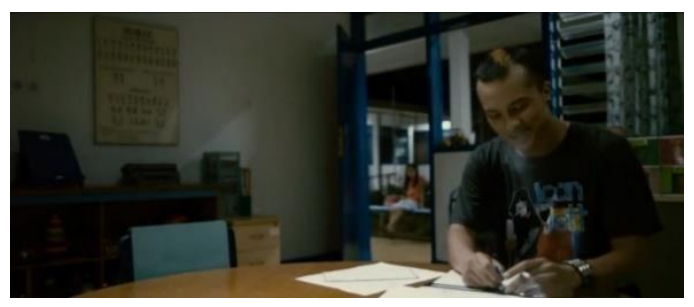

Sumber: Film Don't Talk Love

Gambar 1. Edo menulis surat braille

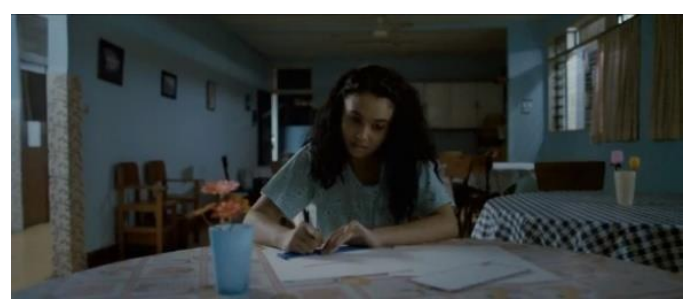

Sumber: Film Don't Talk Love

Gambar 2. Fitri menulis surat braille

Hal ini mungkin berbeda pada saat Edo, seorang bisu-tuli yang membeli rokok di minimarket dan berkomunikasi dengan kasir yang merupakan orang dengar. Ketika pesan Edo untuk menanyakan rokok yang biasa dibeli perempuan dengan bahasa isyarat tidak diterima oleh kasir karena ia awam dan tidak mengerti bahasa isyarat di situlah pesan tidak tersampaikan. Kesuksesan proses komunikasi ini pada dasarnya ditentukan oleh "kemampuan" kedua belah pihak dalam berkomunikasi. Ketika orang dengar atau orang nondisabilitas "tidak mampu" berbahasa isyarat sehingga Edo harus mengulangi pertanyaannya dan pada akhirnya kasir memberikan kertas untuk menjembatani komunikasi antara mereka, terlihat bahwa disabilitas ditunjukkan pada bagaimana "hambatan" ini diciptakan oleh struktur atau lingkungan yang tidak inklusif bagi penyandang disabilitas untuk secara mandiri berpartisipasi di masyarakat.

Adegan ini merupakan cara untuk menyampaikan posisi penyandang disabillitas, dalam hal ini penyandang disabilitas rungu-wicara di masyarakat. Bagaimana cara berkomunikasi mereka dianggap liyan dan sengaja dipilih untuk dipinggirkan oleh struktur (bahasa isyarat bukan bahasa yang dapat dipelajari atau dipergunakan dalam keseharian masyarakat ataupun di ruang-ruang publik). Wacana atas pengesampingan hak-hak dan terbatasnya akses penyandang disabilitas rungu-wicara dalam berkomunikasi di masyarakat dimunculkan dalam adegan ini, tanpa terasa menggurui dan subtil.

Hal ini kemudian memperlihatkan bahwa pada film ini, disabilitas tidak ditunjukkan pada sesuatu yang menubuh atau hambatan yang dialami oleh penyandang disabilitas melainkan merujuk pada lingkungan yang tidak inklusif untuk penyandang disabilitas, pada saat itulah mereka menjadi disable. 


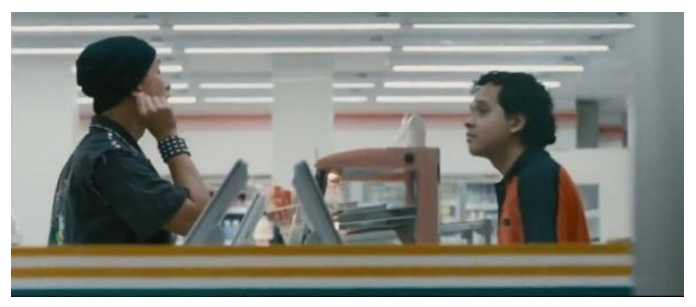

Sumber: Film Don't Talk Love

Gambar 3. Edo bertanya pada kasir

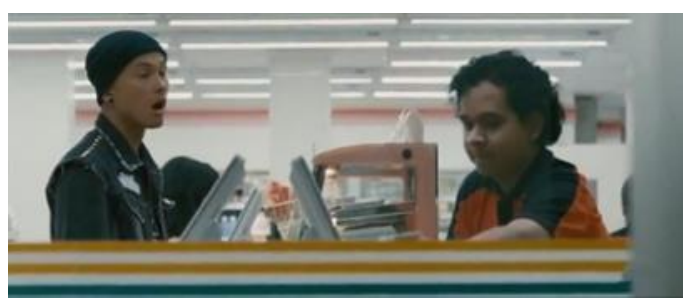

Sumber: Film Don't Talk Love

Gambar 4. Kasir mencari kertas untuk berkomunikasi dengan Edo

Identitas juga kemudian dapat dilihat pada bagaimana hubungan-hubungan antar karakter yang terjalin dalam cerita. Bagaimana kedekatan-kedekatan ini menunjukkan posisi subjek karakter penyandang disabilitas. Pada relasi sosial penyandang disabilitas dalam film ini, ditemukan bahwasanya ada wacana yang hendak didistribusikan melalui film mengenai penyandang disabilitas sebagai makhluk seksual dan berdaya atas tubuhnya atau dalam penelitian ini eksplorasi diri.

Pada tokoh Diana misalnya, menerima menars (menstruasi pertama kali) sebagai sebuah tanda bahwa ia "akhirnya menjadi wanita". Menurut penulis hal ini merupakan usaha untuk memunculkan adanya perayaan dan penerimaan perempuan atas keperempuanannya. Sebagai figur ibu yang merupakan perempuan dewasa atau disebut Diana sebagai wanita, ibu Diana cukup mengenalkan Diana terhadap menstruasi, terlihat pada bagaimana ibunya membelikan Diana pembalut. Hubungan ibu Diana dan Diana yang terbuka mengenai menars dan menstruasi secara umum membuat Diana memiliki penerimaan yang positif terhadap menstruasinya; terhadap keperempuanannya. Pada bagian ini, film berusaha untuk mewacanakan mestruasi.

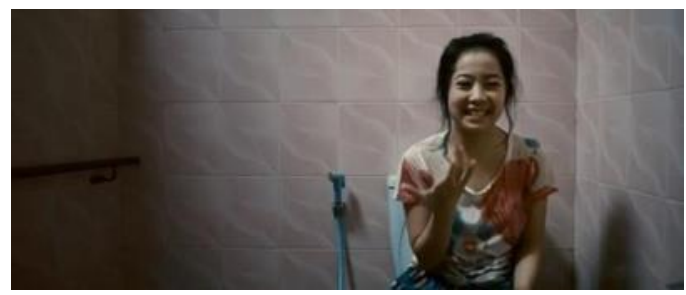

Sumber: Film Don't Talk Love

Gambar 5. Diana mengalami menars 


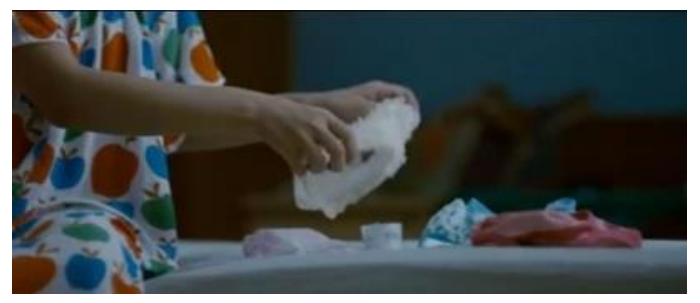

Sumber: Film Don't Talk Love

Gambar 6. Ibu Diana membelikan ia pembalut

Pada persoalan eksplorasi tubuh seorang gadis bernama Fitri dalam film ini misalnya, adalah upaya menghadirkan kembali sisi-sisi humanis yang absen diberikan pada banyak kesempatan oleh media, utamanya film. Bahwa eksplorasi tubuh berikut hasrat seksual yang inheren pada dirinya ditampilkan melalui hubungan-hubungannya dengan lawan jenis. Pada hubungan Fitri dengan Edo ditunjukkan pada saat Fitri dan Edo yang tengah berciuman di kamar bilas, Fitri menghentikan Edo yang tengah menciumnya, lalu ia secara aktif mencium Edo. Hal ini merupakan salah satu adegan kunci yang menunjukkan bahwa Fitri adalah gadis yang sedang mengeksplorasi dirinya, ia secara aktif dan sadar menunjukkan sisi seksualitas dari dirinya, adegan ini juga menjadi salah satu cara dalam menyampaikan bahwa penyandang disabilitas dalam hal seksualitas bukan hanya menjadi "korban" atau objek, melainkan juga menjadi subjek dan memiliki dorongan seksualitas pula.

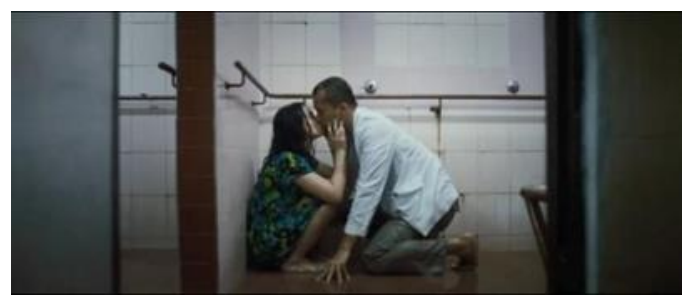

Sumber: Film Don't Talk Love

Gambar 7. Fitri mencium Edo di kamar bilas

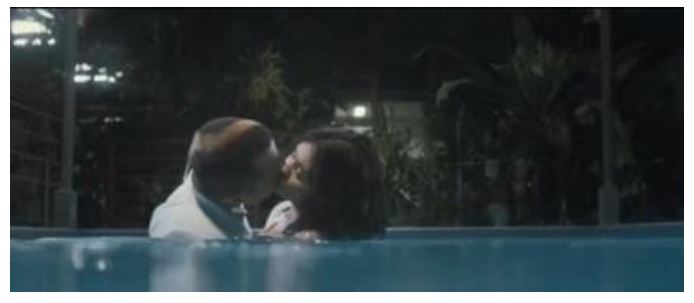

Sumber: Film Don't Talk Love

Gambar 8. Fitri dan Edo berciuman

Berdasarkan pemaparan-pemarapan yang telah disebutkan sebelumnya maka identitas disabilitas dalam film ini ditunjukkan melalui interaksi sosial sebagai sesuatu yang tidak menubuh melainkan lingkungan yang tidak inklusif, melalui relasi sosial penyandang disabilitas diperlihatkan sebagai makhluk seksual dan berdaya atas tubuhnya, dan melalui representasi karakter yang dapat ditemui di masyarakat atau penggambaran cerita yang dijumpai dalam keseharian. 


\section{PENUTUP}

Identitas disabilitas dalam film ini ditunjukkan melalui interaksi sosial sebagai sesuatu yang tidak menubuh melainkan lingkungan yang tidak inklusif, melalui relasi sosial penyandang disabilitas diperlihatkan sebagai makhluk seksual dan berdaya atas tubuhnya, dan melalui representasi karakter yang dapat ditemui di masyarakat atau penggambaran cerita yang dijumpai dalam keseharian.

Pertama, menurut penulis terdapat tema besar yang hendak didistribusikan melalui film ini, yaitu inklusivitas. Inklusivitas berusaha ditampilkan melalui penggambaran karakter yang dapat ditemui di masyarakat maupun penggambaran cerita atas karakter tersebut yang terjadi di keseharian masyarakat. Namun, perlu dikaji kembali inklusivitas ini pada alasan pembuat film dalam pemilihan hampir seluruh aktor dan aktris yang memerankan tokoh penyandang disabilitas memiliki ciri fisik yang rupawan.

Kedua, film ini juga memberikan wacana pemaknaan yang lain dari disabilitas, ia ditampilkan bukan sebagai hambatan atau kelemahan. Disabilitas juga tidak diperlihatkan sebagai suatu konsep yang melekat pada tubuh (menubuh) seorang penyandang disabilitas. Dengan kata lain, film ini berusaha untuk menggoyahkan wacana yang sudah mapan di media bahwa penyandang disabilitas adalah kelompok yang lemah atau bertubuh "aneh". Hal ini diperlihatkan melalui penggambaran tokoh-tokoh penyandang disabilitas yang mandiri dan memiliki kehidupan sebagaimana kehidupan remaja pada umumnya. Alih-alih memperlihatkan disabilitas sebagai suatu hambatan atau kecacatan, film ini menunjukkan bahwa hambatan yang dialami oleh penyandang disabilitas adalah hasil dari lingkungan yang tidak inklusif, tidak memberikan akses atau kesempatan kepada mereka untuk aktif berpartisipasi dengan kondisi yang mereka miliki.

Ketiga, penulis menemukan bahwa film ini menunjukkan penyandang disabilitas yang memiliki daya atas tubuhnya dan dalam hal seksualitas bukan hanya menjadi objek, melainkan juga menjadi subjek yang memiliki dorongan seksualitas. Selain itu, menstruasi diperlihatkan sebagai sesuatu hal yang lumrah dan disambut dengan suka cita menunjukkan bahwa perempuan disabilitas adalah makhluk seksual yang organ reproduksinya berkembang. Kedua hal ini merupakan cara film ini mendistribusikan wacana seksualitas dan eksplorasi tubuh penyandang disabilitas yang kerap menjadi wacana yang dipinggirkan dalam pembahasan mengenai wacana disabilitas.

\section{DAFTAR PUSTAKA}

Bernardi, D. (2009). Filming Difference. University of Texas Press.

De Fina, A. (2006). Introduction. In D. Schiffrin, M. Bamberg, \& A. De Fina, Discourse and Identity. Cambridge University Press.

Ellis, K., \& Kent, M. (2010). Disability and New Media. Routledge.

FFD. (2018). FFD 2018 Luncurkan Program Tentang Disabilitas. FFD. https://ffd.or.id/newsletter/ffd- 2018-meluncurkan-program- khusus-tentang-disabilitas/

Fitranisa, I. (2016). Membaca Film Indonesia Bertema Religi (Studi Film Discourse Interpretation tentang Identitas Keislaman dalam Film 99 Cahaya di Langit Eropa dan Haji Backpacker). Universitas Airlangga.

Hall, S. (1996). Introduction: Who Needs "Identity"? In S. Hall, \& P. D. Gay, Questions of 
Cultural Identity. SAGE Publisher.

Hall, S. (1997). Representation: Cultural Representations and Signifying Practices. SAGE in association with Open University.

Kellner, D. (1995). Media Culture: Cultural Studies, Identity, and Politics between the Modern and the Post-Modern. Routledge.

Kolker, R. (1998). Film, Form, and Culture. McGraw-Hill.

Movanita, A. N. K. (2017). Tunanetra dan bisik-bisik di Bioskop Bisik. Kompas.Com. https://nasional.kompas.com/read/2017/07/17/07162081/tunanetra-dan-bisik-bisik-dibioskop-bisik-.

Thaniago, R. (2018). Bolehkah Saya Menjumpai Difabel di Media dengan Layak? Www.Remotivi.or.Id. http://www.remotivi.or.id/amatan/503/bolehkah-saya-menjumpaidifabel-di-media-dengan-layak

Thompson, R., \& Bowen, C. (2009). Grammar of the Shot. Elsevier Inc.

Turner, G. (1999). Film as Social Practice. Routledge.

Villarejo, A. (2007). Film Studies, the Basic. Routledge.

Wildfeuer, J. (2014). Film Discourse Interpretation. Routledge.

Wood, L. (2012). A Critical Analysis Media Representation of Disabled People. Disabilityplanet. http://www.disabilityplanet.co.uk/c ritical-analysis.html 